\title{
La geopolítica contemporánea de Estados Unidos y el fin de Centroamérica
}

\section{The Contemporary Geopolitics of United States and the End of Central America}

\section{A geopolítica contemporânea dos Estados Unidos e o fim da América Central}

Omar Santiago Herrera-Rodríguez

Docente e investigador

Universidad de Costa Rica

Sede de Occidente

Recibido: 5/3/2017 Aceptado: 10/4/2017

\section{Resumen}

En el presente trabajo se examinan, en seguimiento a las reflexiones del artículo publicado en el número anterior, una serie de medidas económico-políticas implementadas por Estados Unidos en el marco preparativo y en ejecución de la Guerra Global contra el Terrorismo, con los objetivos de demostrar que Mesoamérica toma el lugar que en décadas anteriores ocupó Centroamérica como foco de interés y atención particularizado de la geopolítica y economía estadounidense. Se propone que esta reconfiguración regional se circunscribe a una revolución espacial

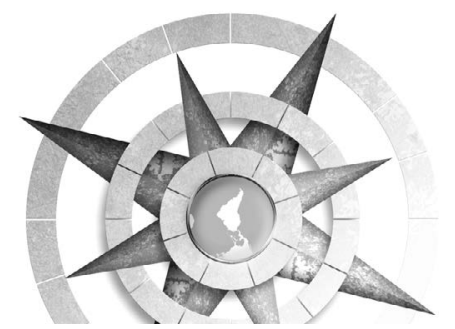

planetaria que es consecuencia inmediata de la Guerra Global contra el Terrorismo.

Palabras clave: Centroamérica, Mesoamérica, guerra, terrorismo, terror de Estado, Estados Unidos, América Latina

\section{Abstract}

In follow-up to the reflections of the article published in the previous issue, the present paper considers a series of political and economic measures that the United States implemented in the preparation and launch of the global war against terrorism; the purpose is to prove that Mesoamerica takes the place that Central America occupied in past decades as a particularized focus of interest and attention of the American geopolitics and economy. The paper proposes that this regional reconfiguration is circumscribed to a planetary space revolution, which is an immediate consequence of the global war against terrorism. 
Keywords: Central America, Mesoamerican, war, terrorism, terror, United States, Latin America

\section{Resumo}

Neste artigo, seguindo as reflexões do artigo publicado na edição anterior, uma série de medidas econômico-políticas implementadas pelos Estados Unidos no quadro preparatório e na execução da Guerra Global contra o Terrorismo, com os objetivos de demonstram que a Mesoamérica assume o lugar que, nas décadas anteriores, ocupou a América Central como foco de interesse e atenção particularizada da geopolítica e economia dos EUA. Propõe-se que esta reconfiguração regional esteja circunscrita a uma revolução espacial planetária que seja uma conseqüência imediata da Guerra Global contra o Terrorismo.

Palavras chave: America Central, Mesoamerica, guerra, terrorismo, terrorismo do Estado, Estados Unidos da America, geopolítica da América Latina

\section{Introducción}

En mi artículo anterior, publicado en Temas de Nuestra América 3361 (enero-junio, 2017), desarrollé el marco y el conjunto de las principales medidas políticas y económicas del gobierno estadounidense hacia la región en las décadas de los ochenta y noventa, las cuales conformaron una de las plataformas necesarias para la declaración de la Guerra Global contra el Terrorismo. En el presente artículo, tomando en consideración el desarrollo teórico conceptual y analítico anterior, abordaré lo que he denominado: fin de Centroamérica.

Toda reorganización profunda económico-política del capitalismo como sistema-mundo tiene por correlato una revolución espacial, concepto acuñado por Schmitt (2007), al cual apareja dos ejemplos con alcance planetario: la conquista de América y la conquista británica del mar, donde se dio la separación político-económico-militar de la tierra y el mar como nuevo nomos.

Sostengo pues, que la Guerra Global contra el Terrorismo, en cuanto empresa colonizadora en el nivel planetario conlleva una reconfiguración de las formas de composición histórico-social del espacio y de la consciencia que sobre este tenemos. El desdibujamiento de Medio Oriente por las guerras internas y de intervención, el incremento indefectible e imparable de las migraciones, los desplazamientos de población refugiada hacia Europa y las políticas de vigilancia, control e inversión en Mesoamérica por parte de Estados Unidos, son las manifestaciones visibles del fenómeno.

66 La geopolítica contemporánea de Estados Unidos y el fin de Centroamérica

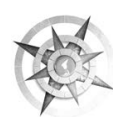


En razón de lo anterior, Centroamérica como región geopolítica cuya relevancia para los intereses geoestratégicos estadounidenses tuvo un lugar central a lo largo del siglo XX, es ampliada en sus márgenes para incluir a México, Panamá y Colombia en una sola zona de control geopolítico e inversión/extracción económica como demostraré a lo largo de las próximas páginas.

Sirva indicar, nuevamente, que el presente artículo dividido en dos partes surge de una investigación más amplia titulada Terror de Estado y Guerra Global contra el Terrorismo. Explicación sobre el origen y la constitución de leyes antiterroristas en Centroamérica entre el 2001 y el 2015, la cual corresponde a mi trabajo final de graduación de la maestría en Estudios Latinoamericanos con énfasis en Cultura y Desarrollo del Instituto de Estudios Latinoamericanos de la Universidad Nacional de Costa Rica, a cuyos docentes y planta administrativa debo especial gratitud.

\section{Centroamérica como una espe- ranza sin consumar}

Decir fin de Centroamérica, es un juicio provocativo y arriesgado, especialmente por el carácter instalado del concepto en el nivel investigativo a la hora de realizar abstracciones regionales. Siendo así, Centroamérica o Mesoamérica (alternativa que sugiero desde un punto de vista geopolítico para comprender el marco regional en las relaciones de Estados Unidos con estos países a partir de la Guerra Global contra el Terrorismo) son ambos conceptos abstractos que encierran realidades diferenciadas y complejas que no necesariamente se integran a la hora de ser enunciadas.

Bajo esta mirada, cabe cuestionar si Centroamérica tiene un auténtico correlato material o si por el contrario, las limitaciones al respecto le dan mayor fortaleza a la idea de Mesoamérica como nueva zona geopolítica configurada a partir de las políticas estadounidenses en el milenio presente, en asociación con las oligarquías nacionales de los distintos países mesoamericanos y como marco analítico-investigativo intra, inter y supra regional.

Como punto de partida, resulta llamativo identificar que, detrás del sueño del proyecto independentista de Simón Bolívar comúnmente situado en América, pero asociado a Suramérica principalmente, el propio Bolívar reconoce en las Cartas de Jamaica las dificultades de dicho proyecto y por el contrario, encuentra factible la unificación del istmo que va de Panamá a Guatemala:

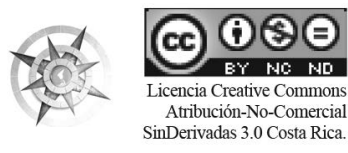

La geopolítica contemporánea de Estados Unidos y el fin de Centroamérica 
Los estados del istmo de Panamá hasta Guatemala formarán quizá una asociación. Esta magnífica posición entre los dos grandes mares podrá ser con el tiempo el emporio del universo, sus canales acortarán las distancias del mundo, estrecharán los lazos comerciales de Europa, América y Asia; traerán a tan feliz región los tributos de las cuatro partes del globo. ¡Acaso sólo allí podrá fijarse algún día la capital de la tierra, como pretendió Constantino que fuese Bizancio la del antiguo hemisferio! (Bolívar, 198, p. 85).

Bolívar acertó en la parte más sencilla: la riqueza ambiental y lo valioso de la ubicación geográfica del istmo; sin embargo, no consideró que estas ventajas serían igualmente pensadas-deseadas por Inglaterra durante el siglo XIX y Estados Unidos en el siglo XX, quienes contaron con el apoyo y beneplácito de parte de las oligarquías locales de cada país para controlar los recursos internos y garantizarse una posición geoestratégica en la arena de las relaciones internacionales tanto políticas como comerciales.

Con ello, la mayor parte de la población del istmo nunca llegó a ver una Bizancio centroamericana o saber siquiera qué o quién era Bizancio; sino por el contrario, ha debido experimentar violentas dictaduras, regímenes oligárquicos que han empobrecido la vida de las mayorías, concentrado el poder y medios de producción en pocas manos y la débil conformación (con excepción de Costa Rica) de instituciones democráticas y de Derecho.

Contrariamente a las expectativas por unificar el istmo promovidas a partir de los procesos independentistas desde los sectores progresistas-liberales, esta posición desde el inicio perdió hegemonía al lado de las posturas separatistas, localistas y posteriormente nacionalistas de los distintos países, a la vez que el poder unificador de la Capitanía General de Guatemala durante la colonia se fue disolviendo desde los primeros años de vida independiente, tal como lo evidencia el asesinato de Francisco Morazán en 1842 en San José, Costa Rica.

El detallado estudio desarrollado por el economista hondureño Alcides Hernández (1994), da cuenta del extenso recorrido de los procesos integracionistas a lo largo del siglo XIX y XX. Durante el siglo XIX, la debilidad económica de cada país se vio estimulada por el separatismo, generando que estos se insertaran [fueran insertados] en el mercado internacional y la división internacional

68 La geopolítica contemporánea de Estados Unidos y el fin de

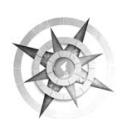


del trabajo en forma desfavorable; con una marcada tendencia a la super-explotación de las amplias masas poblacionales de forma paralela al incremento de la inversión extranjera y el control, mediante oligopolios y oligopsonios de las economías locales.

De igual manera señala que, la iniciativa del Mercado Común Centroamericano (MCCA) estimulada por la CEPAL “...como alternativa para expandir el mercado regional, y estimular la diversificación productiva y la creación de oportunidades para los trabajadores y los pequeños y medianos productores" (Hernández, 1994, p. 16), no llegó a concretarse ni rindió los frutos esperados.

Por el contrario, la única integración experimentada en la región ha sido solo en términos de articulación y beneficio para los grupos oligárquico-empresariales de la religión, excluyendo así a la mayoría de la población: “...se busca la integración para maximizar el negocio de los grupos económicos más poderosos." (Hernández, 1994, p. 16).

Cabría, en este sentido, afirmar que Centroamérica, vista desde los procesos de integración regional nunca ha existido y que a la fecha, imperan las posturas separatistas aunque hubo momentos en los que los Estados han tenido acercamientos. Sin embargo, en la actualidad, se presentan condiciones desfavorables que contribuyen a reforzar la histórica distancia entre los países que conforman el Sistema de Integración Centroamericana.

El primero de ellos lo demarca la actual crisis migratoria que ha puesto en importantes puntos de tensión y desacuerdo a todas las naciones que conforman el SICA, ocasionando incluso la salida momentánea de la representación costarricense de dicho órgano bajo el mandato de Luis Guillermo Solís durante el 2016, otrora impulsor de dicha instancia durante la década de los noventa y el cierre de fronteras con reforzamiento militar (Nicaragua hacia Costa Rica) y policial (Costa Rica hacia Panamá).

La falta de cooperación intrarregional para la solución del incremento del tránsito de personas por los distintos territorios evidencia la poca capacidad de diálogo, solidaridad y resolución entre todas las partes sobre un tema neurálgico en la actualidad que es insoslayable para el istmo por su carácter de puente geográfico.

El segundo punto, como demuestra Cascante (2014), refiere a las debilidades presentes en los procesos de integración regionales en torno a la 
constitución de una efectiva instancia supranacional en materia judicial, so pena de la consideración sobre las limitaciones que posee la Corte Centroamericana de Justicia para la resolución de conflictos limítrofes.

La incapacidad de este órgano de hacer vinculante una resolución, sea por la falta de recursos político-diplomáticos, político-coercitivos o económicos, hace de la Corte Centroamericana de Justicia una instancia ornamental en el andamiaje del Sistema de Integración Centroamericana, ocasionando que los países de la región prefieran a la Corte Internacional de Justicia (CIJ) para la resolución del principal conflicto entre naciones: los problemas limítrofes-fronterizos.

Este último es el tercer punto que demuestra la desintegración entre los países de la región. La Corte Internacional de Justicia ha recibido trece casos en total desde 1951, en materia de administración de fronteras y conflictos limítrofes. Cascante (2014) señala que la mayoría de estos conflictos datan desde el siglo XIX; es decir, solo en disputas territoriales hay por lo menos siglo y medio de conflictos no resueltos entre países, que dan cuenta del agotamiento e inviabilidad de la discusión político-diplomática y demuestran la capacidad limitada de una instancia suprarregional judicial.

Más preocupante todavía es que las resoluciones brindadas por la $\mathrm{CIJ}$ son apropiadas por los países como sinónimo de "triunfo" y en consecuencia de "derrota" para el adversario. Esta lógica de enemigos solo sedimenta el distanciamiento entre países, como ha ocurrido durante el último lustro entre Costa Rica y Nicaragua a partir de los conflictos por el dragado del Río San Juan y la disputa de Isla Calero, donde ambas partes celebraron su "triunfo" en la CIJ.

El cuarto y último elemento a considerar aquí, proviene de la debilidad del desarrollo económico de cada país al lado de la debilidad o inexistencia de mecanismos de integración económica parcial o completa. El fracaso ya mencionado de la conformación de un Mercado Común Centroamericano en las décadas de los sesenta y la no consecución de las metas del Protocolo al Tratado General de Integración Económica Centroamericana firmado en 1993 para paulatinamente construir la Unión Económica Centroamericana, encuentran menos posibilidades de cumplimiento en la actualidad debido a la aprobación

70 La geopolítica contemporánea de Estados Unidos y el fin de Centroamérica

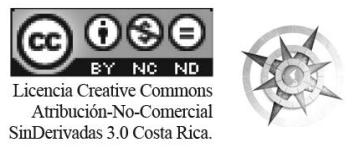


del (DR-CAFTA $)^{1}$ con Estados Unidos, el cual desplaza los esfuerzos por generar una zona prioritaria de comercio a lo interno de la región y de unión aduanera, para en su lugar, favorecer a las disposiciones e intereses del gobierno estadounidense.

De esta manera y en términos efectivos, es difícil hablar de la existencia de Centroamérica vista o construida desde sí misma. Por otro lado, ahora vista desde los intereses de las potencias imperialistas, Centroamérica representó en el ámbito económico y geopolítico durante el siglo XIX y el siglo XX una zona de importancia, por lo que ha sido configurada como territorio de disputa. De ahí que haya cobrado pertinencia conceptual-analítica para comprender el lugar que ocupaba la región en las relaciones Centro-Periferia en el nivel internacional, en las que por supuesto, cada país desarrolló procesos particularizados, aunque compenetrados en dinámicas similares.

De suyo, las preocupaciones originadas por la toma del poder del Frente Sandinista de Liberación Nacional (FSLN) en Nicaragua y el avance del Frente Farabundo Martí para la

1 Dominican Republic-Central America Free Trade Agreetment, en inglés) o TLC (Tratado de Libre Comercio entre República Dominicana, Centroamérica y Estados Unidos de América, en castellano).
Liberación Nacional (FMLN) en El Salvador, motivaron a Estados Unidos a conformar la Comisión Kissinger para Centroamérica, en la medida que esta región encuentra un valor especial para el proyecto imperialista estadounidense. Lo anterior porque la pérdida de uno de sus territorios tradicionales de dominación (Nicaragua bajo la familia Somoza) podía ocasionar un efecto dominó en toda la región por la cercanía entre uno y otro país, razón por la cual, el conflicto armado y su posterior resolución diplomática siempre fue determinada y confinada al marco espacial interno de Centroamérica.

Sin embargo, durante el siglo XXI el gobierno estadounidense ha adoptado medidas geopolíticas y económicas que han ensanchado esta forma de regionalización, revolucionando las formas espaciales de los dos siglos anteriores y ha delimitado su perímetro de control fuerte al territorio comprendido entre México y Colombia.

Existe pues, una relación causal entre la Guerra Global contra el Terrorismo y la capacidad del imperialismo estadounidense de revolucionar el espacio en la época actual. Estas no solo lo llevan a emprender y apuntar a una nueva era de colonización del espacio fuera del planeta Tierra relativizando este campo de fronteras, 
sino que, Estados Unidos posee el poder y la fuerza para penetrar y reconfigurar los límites de los Estados-Nación por tierra, mar y aire.

De la misma manera que las potencias europeas reconfiguraron al continente africano a través de su repartición colonial en el siglo XX; Estados Unidos desde la década de 1990 ha comenzado a flexibilizar y relativizar las dimensiones espaciales del territorio marítimo-terrestre comprendido entre México y Colombia, a través del cual despliega no solo un importante contingente militar para la lucha contra el narcoterrorismo, sino también, construye un sistema de comunicación y de carreteras amplio para el tránsito de mercancías y explotación de recursos naturales.

La firma de tratados de libre comercio y proyectos económicos regionales ha hecho que un intelectual como Saxe-Fernández (2001) hable de Mexamérica para identificar una macro-regionalización que comprende a México-Estados Unidos-Canadá a partir del Tratado de Libre Comercio de América del Norte (TLCAN). Por su parte, González (2013) identifica un movimiento análogo en la conformación de Mesoamérica, a partir de la aprobación del Plan Puebla Panamá y su modificación-integración al Proyecto Mesoamérica como la nueva demarcación económica y geopolítica que responde a los intereses contemporáneos imperialistas de Estados Unidos.

Aquí, la noción de Mesoamérica es extendida hasta el Estado colombiano, en la medida que se consideran razones como: 1) reforzar la seguridad de la región en la guerra contra el narcoterrorismo, 2) el control y disputa por la industria-comercio de drogas, 3) el aislamiento y vigilancia hacia el gobierno venezolano, 4) la constitución de un bloque de contraste con los procesos de integración en Suramérica y 5) la consolidación de zona de inversión segura en el marco de las disputas económicas con el Conjunto formado por Brasil, Rusia, India, China y Sudáfrica (BRICS), estrategia paralela al debilitamiento del gobierno de Dilma Rousseff, en cuanto amenaza espacialmente próxima a los intereses estadounidenses en América Latina; de la misma manera que ocurrió con la administración de Fernando Lugo en Paraguay.

De esta manera, examinaré a continuación una serie de medidas políticas y económicas implementadas por el gobierno estadounidense con apoyo de las élites empresariales-políticas de los distintos países

72 La geopolítica contemporánea de Estados Unidos y el fin de Centroamérica

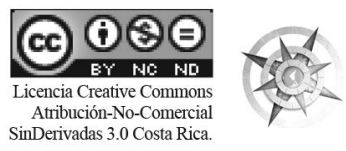


mesoamericanos, que han contribuido a difuminar la espacialidad de Centroamérica como espacio geopolítico y económico fundamental para los intereses imperialistas y que han dan dado paso a la conformación de Mesoamérica como espacio sustituto.

\section{La conformación de nuevos límites}

La clave para identificar los límites que conforman el área mesoamericana como zona geopolítica y económica producida por los intereses imperialistas estadounidenses en América Latina se encuentra en la implementación del Plan Colombia de 1999 y la Iniciativa Mérida del 2008. Mediante estos programas Estados Unidos reconfiguró su geopolítica de control y vigilancia hacia Centroamérica, México y Colombia, utilizando la guerra contra el narcoterrorismo como caballo de batalla.

De forma llamativa, la guerra contra el narcoterrorismo se ubica y desenvuelve lejos de las fronteras estadounidenses bajo el argumento de la seguridad de su territorio, aunque este sea el foco de compra y consumo del área. No obstante, reforzar la seguridad y la militarización del área mesoamericana para combatir a este nuevo enemigo ha demostrado por casi dos décadas de implementación su total ineficacia.

Por el contrario, la función de esta guerra consiste en proteger y controlar los mercados y zonas de tránsito de comercio, garantizar la posesión de los recursos naturales de la región y la vigilancia prioritaria de los gobiernos de Venezuela, Bolivia, Ecuador, Argentina y Brasil, los cuales durante la primera década del nuevo milenio asumieron políticas y líneas distanciadas de algunas de las medidas interpuestas por el gobierno de Estados Unidos y de los organismos financieros internacionales.

Asimismo, dicho control y vigilancia impide que se reactiven fuerzas subversivas y populares en Centroamérica que pudieran articularse con estos países suramericanos y con Cuba, la cual a pesar de no contar con fuerza política o militar significativa, sí posee importancia marítima, además del abastecimiento de azúcar y el capital simbólico que representa: ejemplo de lo anterior lo expresa el golpe de Estado en Honduras en el 2009.

De esta manera, Estados Unidos conformó desde 1999 una red de vigilancia y castigo a lo largo del territorio comprendido entre Colombia y México, desdibujando la región 
centroamericana en un nuevo mapa geopolítico cuyo eje discursivo es la seguridad nacional y hemisférica frente al narcoterrorismo y el crimen organizado; proyecto pensado desde 1988 en el documento Santa Fe II y planificado a lo largo de la década de los noventa a través de la noción de zonas de paz-zonas de libre comercio expuestas en el documento Defense Planning Guidance.

El modo de legitimación de la intervención político-militar estadounidense en Colombia (también utilizada en otros países), remite al concepto de Estado fallido, cuya noción elemental acerca de la incapacidad del Estado para responder a sus propios conflictos, aparece expuesto con claridad en el Plan Colombia: "Las fuerzas desestabilizadoras de narcotráfico han agravado las debilidades de un Estado todavía comprometido en el proceso de consolidación." (Presidencia de la República de Colombia, 1999, p. 4).

Bajo estas condiciones es difícil concebir que la guerra contra el narcoterrorismo financiada por Estados Unidos y ejecutada por el gobierno colombiano de turno se dirija efectivamente contra el tráfico o la producción de drogas, pues la posibilidad de existencia de esta red comercial incluye desde distintos funcionarios del Estado colombiano hasta grandes empresarios internacionales que posibilitan el tráfico, distribución y venta de la misma dentro de Estados Unidos.

En realidad, el Plan Colombia incluye entre sus líneas de acción la apertura e implementación de medidas "estabilizadoras" en el nivel fiscal y comercial de corte neoliberal en detrimento, como lo señala Leech (2007), de programas sociales con miras a la solución de la pobreza y el desempleo que atraviesa el país desde hace décadas. Con ello mantiene la pobreza y el desempleo, condiciones necesarias para que el campesinado se vea obligado a la siembra y cosecha de hojas de coca que serán compradas por precios ridículos por parte de los grandes empresarios del narcotráfico.

En segundo lugar, las reformas e intervención en el ámbito político y económico realizadas en Colombia por Estados Unidos en lugar de fortalecer el entramado institucional político colombiano, lo han debilitado mediante su empequeñecimiento, desfinanciamiento y sometimiento a los organismos financieros internacionales que asumen el control fiscal y financiero del país.

En tercer lugar, el despliegue militar tiene como fines la disputa de

74 La geopolítica contemporánea de Estados Unidos y el fin de 
los territorios controlados por las Fuerzas Armadas Revolucionarias de Colombia (FARC), donde no solo existen zonas de producción de coca sometidas al cobro de impuestos por parte de los grupos guerrilleros hacia el campesinado, sino fuentes de recursos naturales. Asimismo, permite la protección de las empresas transnacionales que con la apertura comercial indicada en el Plan Colombia, extraen petróleo principalmente del departamento de Putumayo, como señalan Tablada y Hernández (2004) y Leech (2007), las cuales han sido atacadas por las FARC y el Ejército de Liberación Nacional (ELN).

Finalmente, el Plan Colombia introduce entre la planificación de sus objetivos de acción una relación entre narcotráfico y terrorismo (objetivo cuatro), lo cual no solo refuerza la condición de organización terrorista declarada por Estados Unidos hacia las FARC en 1997, sino también, permite justificar y legitimar ante la comunidad internacional después de los atentados del 11 de septiembre del 2001 la intervención armada en Colombia hasta la actualidad.

De manera homóloga a Colombia, México ha desempeñado funciones similares para los intereses estadounidenses mediante la aprobación de la Iniciativa Mérida. Este acuerdo, circunscrito en las acciones de Estados Unidos en su Guerra Global contra el Terrorismo, generó una "cooperación" bilateral entre Estados Unidos y México - alcanzando a toda Centroamérica -, para combatir el crimen organizado, el narcotráfico y el terrorismo.

Por medio de una partida presupuestaria de 550 millones de dólares (500 millones para México y 50 millones para Centroamérica) otorgada por el gobierno de Estados Unidos, se plantearon como pilares de la Iniciativa: 1) afectar la organización del crimen organizado, 2) fortalecer las instituciones jurídicas y de seguridad del Estado mexicano, 3) fortalecer y modernizar la estructura fronteriza de vigilancia y 4) generar comunidades fuertes contra el crimen organizado.

La mayor parte del presupuesto se ha destinado a la compra de armamento, incluyendo aeronaves, helicópteros, equipos de inspección y sistemas de telecomunicación; así como al entrenamiento de los cuerpos policiales y militares del país; de manera que fuese creado un bloque de seguridad hemisférica con poder militar comprendido desde México hasta Colombia; pero también, el reforzamiento de la frontera entre México

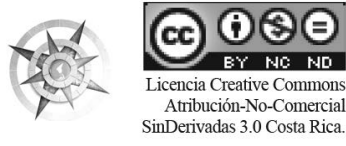


y Estados Unidos, donde la principal población afectada es y sigue siendo la población migrante de toda la región mesoamericana.

En un discurso realizado el 22 de octubre del 2007, la Secretaria de Relaciones Exteriores, embajadora Patricia Castellanos, indicó al respecto de las áreas de trabajo que el gobierno mexicano debe asumir en el marco de la Iniciativa Mérida:

Se identificaron tecnologías de punta, entrenamiento y equipos que, en el marco de un programa de cooperación, contribuirán a los esfuerzos de México, particularmente en tres áreas: la lucha antinarcóticos, combate al terrorismo y administración de fronteras, seguridad pública y procuración de justicia, fortalecimiento institucional y aplicación de la ley (p. 60).

Las tres áreas no son del todo diáfanas en estas palabras, no obstante las podríamos categorizar de la siguiente manera: 1) lucha contra el narcoterrorismo, 2) administración de las fronteras y 3) reforzamiento de la institucionalidad pública, específicamente en materia de justicia y seguridad.

A pesar de la distinción, las tres son medidas relacionadas con el reforzamiento de la seguridad y militarización de la sociedad mexicana que se subsume en el marco de la guerra total contra el narcoterrorismo. De suyo, la vigilancia y reforzamiento sobre la frontera con Estados Unidos es el mejor ejemplo de cómo este último pretende establecer un territorio-escudo que lo blinde de una de las consecuencias inminentes de desarrollar una guerra en Mesoamérica: la migración masiva de población colombiana, centroamericana y mexicana.

Para justificar dichas medidas a lo interno del país, el entonces presidente, Felipe Calderón, apeló al incremento de la seguridad pública y ciudadana de la población ante el clima de inseguridad y a librar a los jóvenes y niños del consumo de drogas; a estas razones subyace la legitimación cultural de las políticas de seguridad por medio de la percepción de inseguridad que tiene la población sobre su propia vida, es decir, al miedo que sienten, obteniendo por contestación del Estado mexicano el incremento de los aparatos represivos y de control.

Paralelamente, como muestra el estudio del sistema jurídico-penitenciario mexicano desarrollado por Calveiro (2012), a partir del año 2009 se anunció la creación de doce centros penales que serían

76 La geopolítica contemporánea de Estados Unidos y el fin de Centroamérica

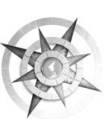


concesionados a empresas privadas; desde este año ha habido un incremento de las penas y de la población penitenciaria del país elevando consecuentemente los índices de hacinamiento y de incumplimiento del sentido moderno del sistema penitenciario: rehabilitar y reintegrar a quien ha delinquido a la sociedad.

La articulación entre esta serie de hechos es evidente: el aumento de las fuerzas policiales-militares en el marco de esta guerra total contra el narcoterrorismo en suelo mexicano ha permitido incrementar el número de arrestos de la población civil y con ello el abastecimiento del negocio que representa la privatización del sistema carcelario. En efecto, los grandes empresarios del narcotráfico representan un número pequeño respecto a la totalidad de personas que conforman las redes del narcotráfico; por lo que, quienes engrosan el número de prisioneros son la población empobrecida mexicana y centroamericana, quienes deben incorporarse a esta red corporativa comercial porque no cuentan con otros medios para subsistir.

Aun cuando no existen criterios ni metodologías para la medición de la percepción de inseguridad, los medios de comunicación de masas se han encargado de construir dicha sensibilidad. La inhibición de la capacidad de agencia y el poder ciudadano es intercambiada por la falsa seguridad establecida por decreto y representada en la figura policial o militar, para ser posteriormente divulgada como la solución factible de la inseguridad.

La contradicción fundamental de este tipo de "soluciones" radica en que el incremento de los aparatos represivos y de los cuerpos normativo-legales tan solo impacta la epidermis del fenómeno y no las condiciones sociohistóricas que lo producen, en cuanto, el sistema del capital y con él, su Estado, son los productores imperativos de la violencia que aterroriza a la población.

Por esta razón, mediante un vuelco de la realidad se presentan como la solución del problema del cual son creadores. A saber, la militarización y tecnologización de los aparatos represivos y la focalización en la judicialización y punición de los conflictos son defendidas como la respuesta al crimen organizado y el narcoterrorismo; mientras que, el efecto real de programas como el Plan Colombia o la Iniciativa Mérida, contribuyen a la reproducción y paulatina agudización de las contradicciones del capital y del Estado moderno ocasionando una espiral que demanda frente

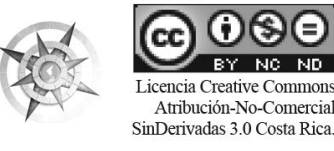

La geopolítica contemporánea de Estados Unidos y el fin de

Centroamérica 
a la explotación, desposesión, violación y asesinato de la mayor parte de la población mesoamericana sumida en la violencia y la pobreza, acciones violentas de contención, terror y represión.

A estas políticas se suman dos programas regionales que se complementan a las medidas anteriormente examinadas: el Plan Puebla Panamá y los Tratados de Libre Comercio son el mejor ejemplo de reconfiguración espacial debido a las necesidades expansivas del capital y de la circulación de mercancías en la actualidad.

\section{Actualización de los puntos de inversión y zonas geopolíticas de control}

El día 12 de setiembre del año 2000 el entonces presidente de México, Vicente Fox, comenzó una gira por los países centroamericanos para presentar y proponer de manera formal el 30 de noviembre del mismo año el Plan Puebla Panamá, cuya implementación comenzó en marzo del 2001. La aparición de dicho plan, de modo coincidente, aparece justo en el momento en que Estados Unidos atraviesa una severa crisis económica.

De esta manera, el Plan Puebla Panamá pone los cimientos de una nueva zona de inversión de capitales transnacionales para la extracción de materias primas y control de rutas comerciales con Europa y el sureste de Asia y una nueva zona de dominio geopolítico al articularse espacio-temporalmente con el Plan Colombia de 1999, constituyendo una plataforma de seguridad y maniobra previa a la declaración de la Guerra Global contra el Terrorismo del 2002; en otras palabras, ambas medidas constituyen una de las condiciones de posibilidad de dicha guerra.

Inicialmente, el Plan Puebla Panamá se estructuraba en ocho iniciativas con diferentes alcances y áreas de inversión; de los cuales, siete se entrelazan en un único objetivo económico: la extracción de recursos naturales de la región mesoamericana, a través de su gestión, mapeo y evaluación, apertura aduanera y comercial, construcción de vías y caminos para la facilitación del transporte de materias primas exportadas y productos con valor agregado importados, explotación de fuentes de generación eléctrica para el sostenimiento de la industria y facilidades para la apertura y control de los lucrativos negocios de telecomunicaciones y seguros en una región cuya población aproximada ronda los 161 395000 millones de habitantes.

78 La geopolítica contemporánea de Estados Unidos y el fin de Centroamérica Omar Santiago Herrera-Rodríguez

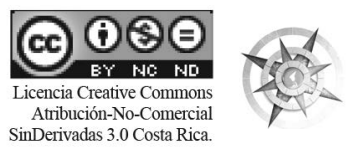


Sin embargo, a partir del 28 de junio del 2008 en el marco de la X Cumbre del Mecanismo de Diálogo y Concertación de Tuxtla, celebrada en Villahermosa, México, el Plan Puebla Panamá fue reestructurado en el nivel institucional-organizacional y renombrado Proyecto de Integración y Desarrollo de Mesoamérica o Proyecto Mesoamérica, hoy vigente. Con ello no solo se abrieron nuevas líneas o iniciativas, sino que se estrecharon lazos con el Sistema de Integración Centroamericana, creando un clima de presión para la aprobación del DR-CAFTA.

Asimismo, en lugar de ocho ejes, el Proyecto Mesoamérica únicamente se divide en dos: uno económico y otro social; permitiendo subordinar lo social si entra en tensión o contradicción con lo económico por un lado, y solapar que, los mayores montos presupuestarios de inversión están efectivamente destinados a lo económico: las áreas transporte y energía ostentan mayores montos presupuestarios en la categoría de proyectos ejecutados y en ejecución que el resto: $2023.3 \mathrm{mdd}$ y 815.0 mdd respectivamente; considerando que el presupuesto total de todas las iniciativas en conjunto es de $3077.4 \mathrm{mdd}$, ambas iniciativas consumen el $92 \%$ de los recursos del Proyecto Mesoamérica.
Además, la ubicación estratégica de los proyectos de construcción de carreteras y de redes de telecomunicaciones evidencia la intención de Estados Unidos de establecer y consolidar su dominio sobre la costa pacífica, principal punto de acceso de países como China y Rusia con quienes disputa el control de rutas comerciales y mercados a través del océano Pacífico.

Con esta medida, Estados Unidos se garantiza una zona de inversión de capitales a lo largo de Mesoamérica para la posterior extracción de recursos naturales que satisfagan las necesidades de su economía. La otra estrategia utilizada en la región fueron los Tratados de Libre Comercio; la cual, para el caso centroamericano, no se restringió a estos países, sino que incluyó a República Dominicana con claros objetivos de garantizar su control del Caribe.

Este tratado comenzó a negociarse el 08 de enero del 2003, apenas unos meses después de la declaración de la Guerra Global contra el Terrorismo. Esta cercanía es fundamental, pues como lo indica Pacheco (2003), el entonces Secretario de Estado estadounidense Collin Powell, declaró que el libre comercio es la mejor arma para controlar el terrorismo.

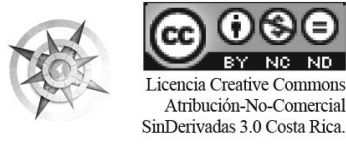

La geopolítica contemporánea de Estados Unidos y el fin de 
La frase anterior posee mayor sentido si se la analiza desde su narración negativa: aquel que oponga resistencia a los tratados de libre comercio simpatizaría por tanto con el terrorismo. Como he mencionado ya, este es el mapa de ruta de la estrategia estadounidense hacia América Latina construido desde inicios de la década de los noventa y que se asienta en el conjunto de medidas aquí examinadas.

El primer elemento a considerar en torno a estas negociaciones comerciales es que el gobierno de Estados Unidos siempre se mantuvo renuente a realizar negociaciones bilaterales y presionó por un tratado regional, frustrando con ello la posibilidad de una integración regional efectiva entre los países centroamericanos y manteniendo de esta manera, su control en un área sumida no solo en la pobreza y el desempleo, sino marcada por los conflictos de intereses entre Estados-nación y una débil estructura jurídica supranacional. Con ello se consiguió imposibilitar aún más la creación de canales de integración necesarios entre los países centroamericanos que a la postre contribuyeran en la conformación de un área político-económica fuerte y unificada.

A estose sumaque lossectoresempresariales-oligárquicos centroamericanos en el marco de la muy breve negociación siempre promocionaron la necesidad inexorable y única de firmar el tratado de libre comercio con Estados Unidos, subordinándose a los intereses de Washington y las grandes corporaciones transnacionales.

El tercer elemento de interés aquí corresponde al capítulo veintiuno de Excepciones, artículo 21.1 donde introduce el concepto de seguridad esencial, sobre el cual únicamente se indica:

Ninguna disposición de este Tratado se interpretará en el sentido de: (a) obligar a una Parte a proporcionar ni a dar acceso a información cuya divulgación considere contraria a sus intereses esenciales en materia de seguridad; o (b) impedir que una Parte aplique medidas que considere necesarias para cumplir con sus obligaciones respecto al mantenimiento o la restauración de la paz y la seguridad internacional, o para proteger sus intereses esenciales en materia de seguridad.

El segundo de los ítems resulta alarmante en relación con las soberanías nacionales de los países inscritos al Tratado. La imposibilidad de apelar a la autodeterminación soberana a lo interno de las fronteras de cada país, no solo transgrede y destruye la

80 La geopolítica contemporánea de Estados Unidos y el fin de Centroamérica

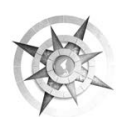


constitución de un Estado-nación, sino que niega la relación de paridad entre cuerpos políticos semejantes para dar paso a un imperio con legitimidad de acceso e intervención del territorio que comprenda el acuerdo.

Si a esto se suma que el procedimiento de intervención en materia de seguridad no es el de cada uno de los Estados, sino el de la parte que busca proteger sus intereses esenciales en materia de seguridad y cumplir sus obligaciones, lo que está de fondo es la aplicación de la Ley Patriota en los países centroamericanos y República Dominicana, en la cual fueron expandidos los poderes gubernamentales para la confiscación de propiedades (Título I, Sección 203) o la intercepción y uso judicial de comunicaciones orales, escritas o electrónicas por los servicios de inteligencia (Título II), entre otras medidas, que violentan los derechos civiles fundamentales de la población.

Asimismo, el juzgamiento se daría en organismos paralelos al sistema judicial estadounidense denominados tribunales militares - legítimamente constituidos por el Presidente o el Secretario de Defensa de Estados Unidos - una vez que se ha sido identificado (primera violación del principio de inocencia) como terrorista por las Comisiones Militares, tal como lo establece el artículo 948d) del Military Commissions Act del 2006.

Las acciones e intereses económicos estadounidenses, que son los intereses de las grandes corporaciones transnacionales que reproducen el régimen del capital, se articulan con las acciones e intereses geopolíticos del imperio estadounidense en su carrera por el control de los recursos y mercados clave en medio de la competencia con otras potencias mundiales, de ahí que intervengan incluso las formas y procedimientos jurídicos de cada país.

Así, el Plan Puebla Panamá o Proyecto Mesoamérica y el DR-CAF$\mathrm{TA}$, se encuentran circunscritos en el marco de dos crisis económicas en Estados Unidos y una guerra global con carácter ilimitado: la relación de causalidad entre crisis y reconfiguración espacial cobra un nuevo matiz en cuanto, para la circulación y reproducción del capital es indispensable la modificación de la geografía del capital, incluyendo la transformación de los límites entre Estados-nación modernos.

La necesidad de expansión del capital hacia nuevas fuentes de vida conlleva y provoca la destrucción de los límites y las fronteras territoriales

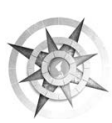


y el redimensionamiento de las concepciones de época sobre el espacio: es el choque de la contradicción de la lógica de la acumulación infinita de capital contra la finitud del planeta donde se desarrolla. Reconfiguración y despliegue que son además posibles por la revolución tecnológica de la segunda mitad del siglo XX y el poderío económico de las grandes empresas y conglomerados transnacionales, los cuales no han existido en ninguna otra etapa del desarrollo de la historia humana.

Estados Unidos demuestra así en la región mesoamericana su poder a través de la violencia, el terror y la guerra total; lo cual al mismo tiempo es expresión y prueba de la crisis estructural del sistema capitalista como patrón de dinamización de las relaciones sociales, en la medida que necesita recurrir a las estrategias coercitivas más violentas para poder sostener su vida en un planeta donde no existe la fuente de la vida eterna.

\section{Conclusiones}

La tesis desarrollada en torno al fin de Centroamérica se planteó en dos términos: 1) mostrar que Centroamérica como tal no ha existido a partir de los esfuerzos internos de los Estados que históricamente la han conformado y que, solo ha tenido un margen de realidad histórica como objeto de los intereses de los países imperialistas y 2) es precisamente por la modificación de estos intereses en la coyuntura presente por la Guerra Global contra el Terrorismo, proyectada y planificada desde finales de la década de los ochenta, que se presenta una revolución espacial en el contexto mundial que reconfigura la región, ampliando sus límites e incorporando a México, Panamá y Colombia.

Esta modificación de la concepción del espacio se manifiesta en las medidas económicas, políticas adoptadas por Estados Unidos desde 1999 en adelante; las cuales, de modo contrario a las décadas anteriores, centran su atención en Mesoamérica y no en Centroamérica solamente.

La guerra total y el terror de Estado como elementos constitutivos de la Guerra Global contra el Terrorismo, son las condiciones de posibilidad de esta reconfiguración espacial en la región; precisamente porque, la expansión y circulación del capital demanda en el marco de la agudización de la crisis sistémica del capital en la que hemos ingresado en el siglo XXI, un mayor uso y en gran escala de la fuerza y la violencia para poder efectivizarse.

82 La geopolítica contemporánea de Estados Unidos y el fin de 
Las consecuencias de esta nueva estrategia de intervención son nefastas para los países mesoamericanos: el incremento de los flujos migratorios, los índices de violencia y homicidios y los índices de pobreza y desigualdad asemejan a los de países que permanecen en una guerra declarada; paralelamente el incremento de la militarización y fortalecimiento de la seguridad de la vida social potencia la permanencia controlada de estas condiciones.

Bajo estas nuevas coordenadas geopolíticas, cualquier proyecto social alternativo, debe considerar el ensanchamiento de los límites espaciales. Si bien, Centroamérica es una promesa y un horizonte para muchos, esta no puede darse sin considerar que está circunscrita a un espacio mayor de control, vigilancia y represión. Quizá esta sea una clave necesaria para que los distintos movimientos sociales de estos países articulen esfuerzos con miras a resistir y levantar una estrategia que contraataque la intervención estadounidense en la región.

\section{Bibliografía}

Bolívar, S. (1985). Contestación de un americano meridional a un caballero de esta isla. Kingston, 6 de septiembre de 1815. En: Bolívar, Simón. Escritos Políticos. Barcelona: Ediciones Orbis.

Calveiro, P. (2012). Violencias de Estado. La guerra antiterrorista y la guerra contra el crimen organizado como medios de control global. Buenos Aires: Siglo XXI Editores.

Cascante, C. (2014). Integración centroamericana, Corte Internacional de Justicia y diferendos limítrofes. Bases para una relación constructiva. En: Soto, Willy y Suárez, Max. Centroamérica: Casa común e Integración Regional. San José: Universidad Nacional-CSUCA.

Comisión Kissinger. (1984). Informe de la Comisión Nacional Bipartida sobre Centroamérica. Ciudad de México D. F.: Editorial Diana.

Congreso de los Estados Unidos de América. (2001). Uniting and Strengthening America by Providing Appropriate Tools Required to Intercept and Obstruct Terrorism (USA Patriot Act) Act of 2001. Washington D. C.

Congreso de los Estados Unidos de América. (2006). Military Commissions Act. Washington D. C.

Consejo de Seguridad Nacional de Estados Unidos. (1992). Defense Planning Guidance. Washington D. C.

Dirección de Servicios de Investigación y Análisis y Subdirección de Política Exterior. (2008). Iniciativa Mérida. 
Compendio. Ciudad de México D. F.: Centro de Documentación, Información y Análisis y Cámara de Diputados.

González, B. (2013). La reconfiguración de Mesoamérica. Una aproximación teórica. Heredia: Documentos de Estudio. Instituto de Estudios Latinoamericanos.

Grupo Técnico Interinstitucional para el Plan Puebla Panamá (BCIE-BIDCEPAL e INCAE). (2001). Plan Puebla Panamá. Iniciativas Mesoamericanas y Proyectos. San Salvador.

Hernández, A. (1994). La integración de Centroamérica. Desde la Federación hasta nuestros días. San José: Departamento Ecuménico de Investigaciones.

Leech, G. (2007). EE.UU., el Petróleo y el (des)orden Mundial. Madrid: Editorial Popular.

Presidencia de la República de Colombia. (1999). Plan Colombia: Plan for Peace, Prosperity, and the Strengthening of the State. Fuente: https://www. usip.org/sites/default/files/plan_colombia_101999.pdf

Saxe-Fernández, J. (2001). Mexamérica: la dialéctica entre la macro y microrregionalización. En: Núñez, Omar; Petras, James; Saxe-Fernández, John y Verltmeyer, Henry. Globalización, imperialismo y clase social. Buenos Aires: Editorial Lumen.

Schmitt, C. (2007). Tierra y mar. Una reflexión sobre la historia universal. Madrid: Editorial Trotta.

Tablada, C. y Hernández, G. (2004). Petróleo, poder y civilización. Madrid: Editorial Popular.

Torres-Rivas. (1977). Interpretación del desarrollo social centroamericano. San José: Editorial EDUCA.

Tratado de Libre Comercio entre Centroamérica, República Dominicana y Estados Unidos. Washington D. C., Estados Unidos.

84 La geopolítica contemporánea de Estados Unidos y el fin de 